\title{
Seven years' experience with suture annuloplasty for mitral valve repair
}

\author{
Tayfun Aybek, MD, Petar Risteski, MD, Aleksandra Miskovic, MD, Andreas Simon, MD, Selami Dogan, MD,
} Ulf Abdel-Rahman, MD, and Anton Moritz, MD, PhD

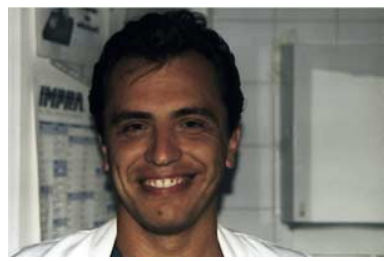

Dr Aybek

See related editorial on page 9 .
Objective: Our early experience with the mural annulus shortening suture procedure for mitral valve repair showed superior hemodynamic performance over ring annuloplasty. The aim of this study was to assess the durability of the mural annulus shortening suture procedure and evaluate our 7-year experience regarding valve function, hemodynamic performance, and clinical outcome.

Methods: Between 1996 and 2003, 222 elective consecutive patients (58.1\% males; age, $59 \pm 14$ years) underwent simple or complex mitral valve repair. Minimal invasive reconstruction was performed in 150 patients. For correction of annular dilatation, we used double-running 2-0 polytetrafluoroethylene sutures to reinforce the posterior circumference of the annulus. Patients were investigated prospectively by means of transthoracic echocardiography before discharge and 1 and 5 years after the operation. The mean follow up was $32 \pm 21$ months (range 1-77 months).

Results: The operative mortality was 3.1\%. Hemodynamic performance at 1 and 5 years showed low mean transvalvular gradients $(2.1 \pm 0.9$ and $2.0 \pm 0.8 \mathrm{~mm} \mathrm{Hg}$, respectively) and a calculated mitral valve orifice area of $3.3 \pm 0.9 \mathrm{~cm}^{2}$ and $3.1 \pm 0.6$ $\mathrm{cm}^{2}$, respectively, with progressive annular dilatation from $31.2 \pm 3 \mathrm{~mm}$ to $33.9 \pm 4$ $\mathrm{mm}$ at 1 year and $35.7 \pm 4 \mathrm{~mm}$ at 5 years $(P<.01)$. Clinical status improved from New York Heart Association class $3.0 \pm 0.4$ to $0.6 \pm 0.8$ at 1 year and $0.8 \pm 0.8$ at 5 years. Freedom form nontrivial residual mitral regurgitation was $82.3 \%$, freedom from reoperation was $95.1 \%$ and actuarial survival was $87.2 \%$, all at 77 months.

Conclusions: The midterm results show satisfactory hemodynamic performance and clinical improvement. Valve competence and reoperation rates are comparable with those of other reports. Durability of the mural annulus shortening suture procedure for mitral valve repair is questioned because progressive annular redilatation occurs.

$\mathrm{M}$ itral valve repair has been reported to be superior over valve replacement in terms of operative mortality, ${ }^{1}$ late survival, ${ }^{2}$ valve-related complications, ${ }^{3,4}$ and preservation of mitral valve function and left ventricular performance. ${ }^{5}$ The most common repair procedures are completed with annuloplasty that not only decreases the diameter of the annulus to increase leaflet coaptation but also reinforces the annulus to prevent future dilatation. In addition, the mitral valve annulus has a sphincter-like function that enlarges its area during diastole by $26 \% .^{6}$ This physiologic flexibility is important for uncompromised left ventricular function and should be preserved in repair attempts. Flexible and partial rings have been introduced to maintain this physiology. ${ }^{7,8}$ A similar strategy, reinforcement of the posterior mitral annulus with sutures, should create minimal rigidity of the mitral ring. In an attempt to avoid the drawbacks of prosthetic ring annuloplasty, like left ventricular outflow tract obstruction ${ }^{9,10}$ or posterior leaflet movement restriction, ${ }^{11}$ suture annuloplasty is still performed by some groups. ${ }^{12-14}$ In 1990, Frater and Sisto ${ }^{15}$ described the mural annulus shortening suture (MASS) 


\section{Abbreviations and Acronyms \\ ePTFE $=$ expanded polytetrafluoroethylene \\ MASS $=$ mural annulus shortening suture \\ NYHA $=$ New York Heart Association \\ SAM $=$ systolic anterior motion}

technique for stabilizing the posterior mitral annulus, a modification of the Paneth-Burr annuloplasty reported earlier. ${ }^{16} \mathrm{We}$ adapted this technique and found excellent early results. The hemodynamic performance was superior after suture annuloplasty compared with that seen after rigid ring annuloplasty in the short-term follow-up, mainly because of the preservation of the intrinsic flexibility of the annulus. ${ }^{17}$

The objective of this report was to assess the midterm durability of the MASS procedure and to present our 7-year experience regarding valve function, hemodynamic performance, and clinical outcome.

\section{Materials and Methods}

\section{Patients}

Between March 1996 and December 2003, 222 elective consecutive adult patients $(58.1 \%$ male subjects; mean age, $59.3 \pm 14.5$ years) with severe mitral valve regurgitation were treated with mitral valve repair by a single surgeon in our department. Suture annuloplasty was used in all repairs except those of ischemic cause with need for overcorrection or calcified rings. Patients with associated severe mitral stenosis, congenital valve lesions, and concomitant aortic valve procedures and emergency cases involving cardiogenic shock were excluded from this prospective study. The baseline characteristics of patients with mitral valve regurgitation and causes are summarized in Table 1. Most patients were in New York Heart Association (NYHA) functional class III. Degenerative disease was the most prevalent cause and was present in $182(82 \%)$ patients. Eleven (5\%) patients had previous cardiac surgery.

\section{Surgical Technique}

In 72 patients a complete median sternotomy and an interatrial approach were performed to access the mitral valve. Cardiopulmonary bypass with moderate hypothermia $\left(28^{\circ} \mathrm{C}-32^{\circ} \mathrm{C}\right)$ was instituted after standard aortic and bicaval cannulation. Myocardial protection was provided by using intermittent antegrade and retrograde cold blood cardioplegia. Standard insufflation of carbon dioxide was instituted with a flow of $2 \mathrm{~L} / \mathrm{min}$ into the operative field by using a Jackson-Pratt drainage (Oriplast GmbH, Neunkirschen, Germany) placed in the pericardium. The interatrial groove was incised, and the left atrium was opened up to its roof.

In 150 patients minimally invasive mitral valve reconstruction was performed through the fourth intercostal space through a small right anterior thoracotomy incision $(7 \mathrm{~cm})$. In these patients the right femoral vessels were used for arterial and venous cannulation. In 15 patients the Port Access System was used (Heartport, Inc, Redwood City, Calif), including an endoaortic balloon catheter for aortic occlusion and aortic root venting. In 135 patients
TABLE 1. Baseline characteristics of 222 patients with mitral valve regurgitation and its cause (means \pm standard deviation)

\begin{tabular}{lc}
\hline Characteristics & \\
Age (y) & $59.3 \pm 14.5$ \\
Sex & \\
Male & $129(58.1 \%)$ \\
Female & $93(41.9 \%)$ \\
Atrial fibrillation & $66(29.7 \%)$ \\
NYHA class & $3.0 \pm 0.4$ \\
EF (\%) & $62 \pm 13$ \\
Redo procedure & $11(5 \%)$ \\
Cause & Patients \\
Degenerative & $182(82 \%)$ \\
Ischemic & $13(6 \%)$ \\
Rheumatic & $18(8 \%)$ \\
Endocarditis & $9(4 \%)$ \\
\hline
\end{tabular}

NYHA, New York Heart Association; EF, ejection fraction.

cardiac arrest was induced by using the technique first described by Chitwood and associates ${ }^{18}$ using a transthoracic crossclamp (Scanlan International, Inc, Minneapolis, Minn) introduced through a 5-mm incision in the third right intercostal space.

As summarized in Table 2, concomitant leaflet procedures were necessary in most patients and were performed by using techniques described by Carpentier and coworkers. ${ }^{19,20}$ The most common procedure was a quadrangular resection of the posterior leaflet. Operations considered complex mitral valve procedures were as follows: additional repair of the anterior leaflet, papillary muscles, or both; artificial chordae implantation; sliding plasty; pericardial patch reconstruction of the anterior leaflet; an additional operation on of the left atrium like volume reduction; the maze procedure; and combined procedures with tricuspid valve repair. Complex mitral valve procedures were performed in $79.7 \%$ of the patients.

For annular reinforcement, we used the MASS procedure, as described by Frater and Sisto, ${ }^{15}$ as an alternative to prosthetic ring implantation. A 2-0 expanded polytetrafluoroethylene (ePTFE) running suture (Gore-Tex, CV-2; W. L. Gore \& Associates, Inc, Flagstaff, Ariz) was passed through the right fibrous trigone and forwarded as a semicircular running suture around the posterior annulus as far as the left fibrous trigone. The same suture was then stepped backward, passing the needle between the stitches of the first suture line and ending at the right fibrous trigone. In general, the amount of tissue compression caused by the running suture resulted in a ring size matching the size and form of the anterior leaflet. Varying the distance between stitches and further tightening or loosening enabled some adjustment of the mitral annulus size, leaving some place for slight overcorrection. Intraventricular injection of saline solution and intraoperative transesophageal echocardiography were performed in all patients to confirm mitral valve competence (5.0-MHz multiplane transducer, Vingmed System Vived Five ultrasound instrument; Vingmed Sound, Horton, Norway). The other surgical details, concomitant procedures, and mean operating, bypass, and aortic crossclamp times are shown in Table 2. 
TABLE 2. Valvuloplasty, additional surgical interventions, and operative times

\begin{tabular}{lc}
\hline Variables & Patients $(\mathbf{n}=\mathbf{2 2 2})$ \\
\hline Valvular or subvalvular repair & \\
Leaflet resection & $148(66.7 \%)$ \\
Bileaflet reconstruction & $22(10 \%)$ \\
Pericardial patch plasty & $18(8.1 \%)$ \\
Gore-Tex chordae implantation & $28(12.6 \%)$ \\
Sliding plasty & $25(11.3 \%)$ \\
Decalcification of the annulus & $15(6.7 \%)$ \\
Concomitant procedure & \\
Myocardial revascularization & $18(8.1 \%)$ \\
Tricuspid annuloplasty & $13(5.8 \%)$ \\
Closure of atrial septal defect & $10(4.5 \%)$ \\
Atrial ablation & $30(13.5 \%)$ \\
Maze procedure & $5(2.3 \%)$ \\
Atrial size reduction & $109(49.1 \%)$ \\
Minimally invasive approaches & $150(67.6 \%)$ \\
Operative times (min) & \\
Crossclamp time & $84 \pm 33$ \\
Cardiopulmonary bypass time & $143 \pm 56$ \\
Operative time & $242 \pm 58$ \\
\hline
\end{tabular}

\section{Postoperative Anticoagulation}

All patients received warfarin at least for the first 6 postoperative weeks; the medication was discontinued in patients with sinus rhythm. In patients with atrial fibrillation, oral anticoagulation was maintained; however, medication during follow-up was at the discretion of referring cardiologists.

\section{Follow-up and Echocardiographic Evaluation}

Follow-up was prospectively and systematically collected by means of annual mailed questionnaires or telephone interview. Clinical and echocardiographic examination in our outpatient clinic was planned at 1 and 5 years after discharge. Functional status was determined according to NYHA classification.

For the purposes of the study, echocardiographic examination was performed intraoperatively, at discharge, and at 1 and 5 years after surgical intervention. Examination included 2-dimensional, M-mode, continuous-wave, continuous, and pulsed, as well as color, Doppler analyses. The examinations were performed with a 3.5-MHz transducer (GE Medical Systems, New Berlin, Wis). All evaluations were carried out according to standard techniques recommended by the American Society of Echocardiography. ${ }^{21}$ Parameters obtained included mean mitral transvalvular gradient, mitral valve opening area as estimated by the pressure half-time method, degree of mitral valve regurgitation, mitral annulus diameter in 4-chamber view, and septolateral dimension during diastole, as well as left ventricular enddiastolic diameter. All parameters were measured 3 times to obtain a mean value by 2 experienced ultrasonographers. The severity of regurgitation was classified as trivial (degree I), mild (degree II), moderate (degree III), or severe (degree IV) and was assessed in a semiquantitative manner by means of color
Doppler flow mapping. Morbidity and mortality are reported as currently recommended. ${ }^{22}$

\section{Data Analysis}

Statistical analysis of the data was performed by using the StatView software package, version 5.0 (SAS Institute Inc, Cary, NC). The Student $t$ test was applied to analyze normally distributed continuous data. Specific differences were isolated by using the Bonferroni correction for multiple comparisons. Values were expressed as means \pm standard deviation. Survival and freedom from event probabilities were estimated with the standard nonparametric Kaplan-Meier method. ${ }^{23}$

\section{Results \\ Operative Results}

Seven $(3.1 \%)$ patients died within 30 days of the operation. Four of them died perioperatively because of low cardiac output syndrome. Two patients had sepsis-induced multiple organ failure. Another patient experienced gastrointestinal bleeding and died during gastroscopy.

The mean operating, cardiopulmonary bypass, and aortic crossclamp times averaged to $242 \pm 58$ minutes, $143 \pm 56$ minutes, and $84 \pm 33$ minutes, respectively.

Four patients had possible damage of the circumflex artery intraoperatively, as suspected on the basis of electrocardiographic and transesophageal echocardiographic findings. Three $(1.4 \%)$ of them had angiographically proved lesions of the circumflex artery. One of these patients had severe ischemia of the posterior wall in the early postoperative course, resulting in emergency coronary bypass grafting to the circumflex artery. The other 3 patients had increased serum cardiac enzymes in stable hemodynamic conditions. A minimally invasive approach was used for their procedures. These patients were clinically and hemodynamically stable and did not undergo an additional revascularization procedure.

Eight $(3.6 \%)$ patients underwent valve replacement during a second pump run after failed mitral valve repair and moderate residual mitral regurgitation. All of them had complex repair attempts as annulus decalcification in 1 patient, restrictive anterior leaflet in 2 patients, and geometric coaptation problems after extensive resection of the posterior leaflet in 3 patients. Six of them were approached in a minimally invasive fashion; SAM was the reason for conversion to replacement in 2 patients. Altogether, we experienced systolic anterior motion (SAM) in 15 patients, as seen with intraoperative transesophageal echocardiography. In 9 of them, the phenomenon disappeared after volume substitution and cessation of inotropic management. Four of the remaining six $(2.8 \%)$ were treated with additional repair.

On the third postoperative day, there was 1 embolic event associated with atrial fibrillation; this resulted in a 


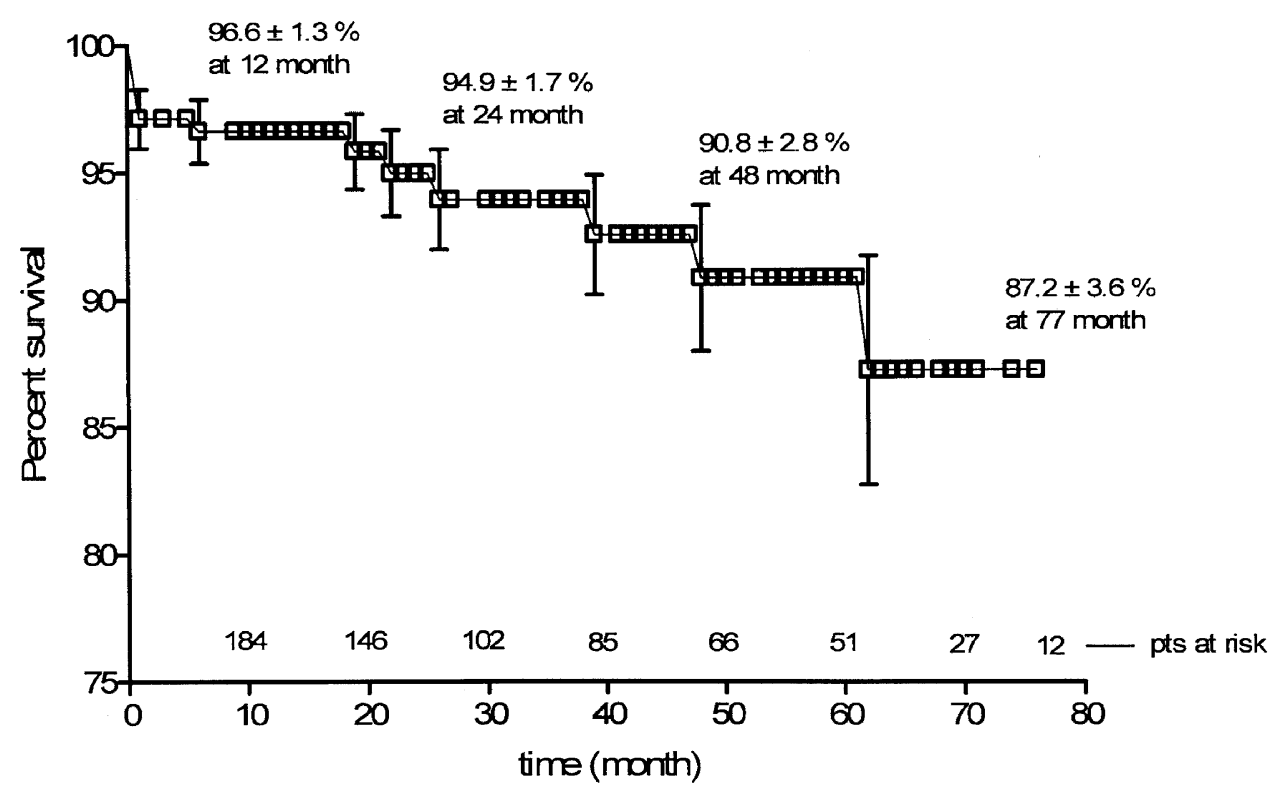

Figure 1. Actuarial survival curve (Kaplan-Meier estimation).

permanent neurologic deficit. Thus far, there has been no additional thromboembolic event of any type.

\section{Patient Survival and Clinical Follow-up}

Two hundred two surviving patients were included in the follow-up. Patients with intraoperative valve replacements after failed repair were excluded. Patients were followed for a total of 573 patient-years. The mean clinical follow-up was $32 \pm 21$ months (range 1-77 months) and was complete in $97.1 \%$ of the surviving patients.

There were 6 late deaths. In 2 patients the reason for death remained unknown; 2 experienced sudden cardiac

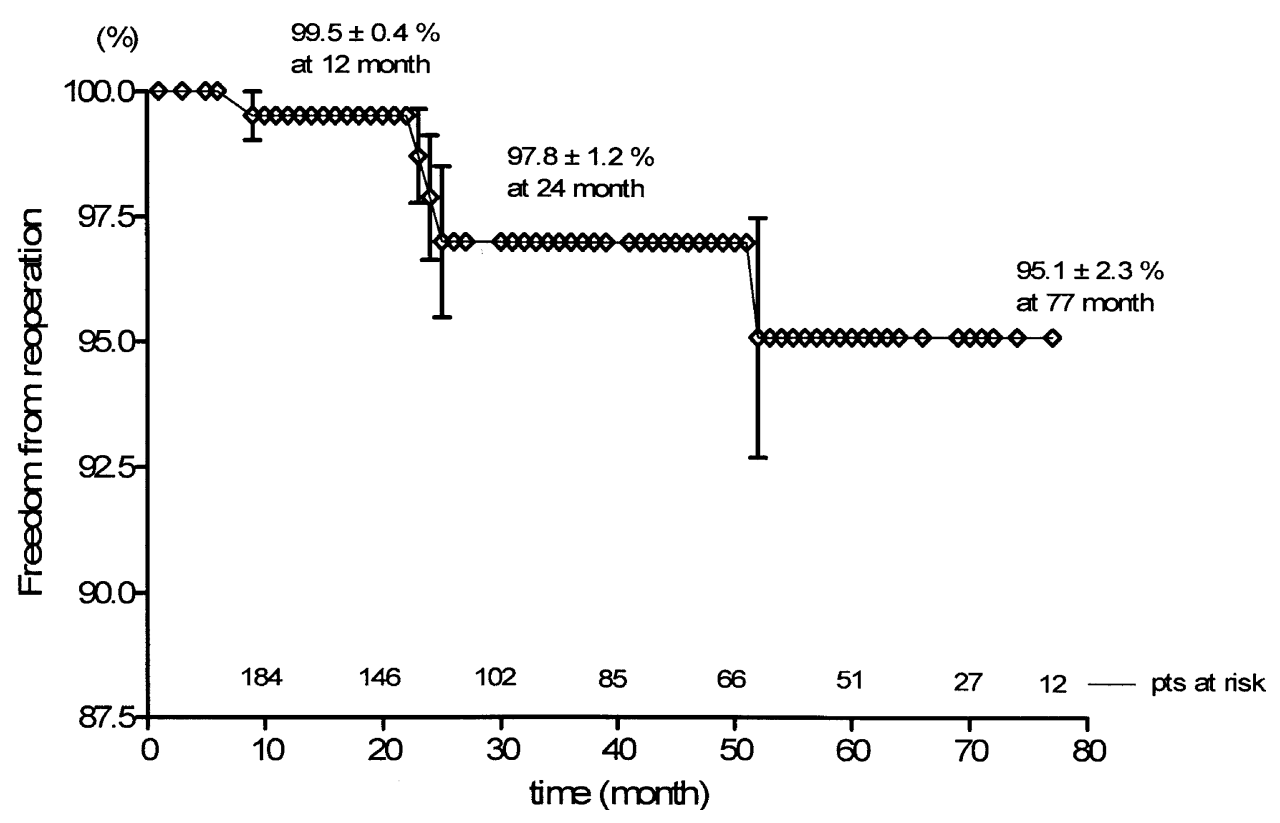

Figure 2. Freedom from reoperation. 
TABLE 3. Echocardiographic and clinical follow-up in patients after suture annuloplasty (means \pm standard deviation)

\begin{tabular}{|c|c|c|c|c|c|}
\hline Variables & $\begin{array}{l}\text { Preoperative } \\
\text { (n = 222) }\end{array}$ & $\begin{array}{l}\text { Discharge } \\
(n=202)\end{array}$ & $\begin{array}{c}1 \text { y postoperative } \\
(n=164)\end{array}$ & $\begin{array}{c}5 \text { y postoperative } \\
(n=48)\end{array}$ & $\boldsymbol{P}$ \\
\hline Mean transvalvular gradients $(\mathrm{mm} \mathrm{Hg})$ & & $2.5 \pm 1.4$ & $2.1 \pm 0.9$ & $2.0 \pm 0.8$ & NS \\
\hline Mitral valve area $\left(\mathrm{cm}^{2}\right)$ & & $3.2 \pm 1.0$ & $3.3 \pm 0.9$ & $3.1 \pm 0.6$ & NS \\
\hline LVEDD (mm) & $56 \pm 7$ & $50 \pm 10$ & $52 \pm 7$ & $49 \pm 6$ & $<.05$ \\
\hline Mitral regurgitation (grade) & $3.1 \pm 1.1$ & $0.25 \pm 0.5$ & $0.34 \pm 0.7$ & $0.64 \pm 1.0$ & NS \\
\hline $\mathrm{MI} \mathrm{I}$ & & $32(16 \%)$ & $23(14 \%)$ & $6(12.5 \%)$ & $\ddagger$ \\
\hline $\mathrm{MI} \mathrm{II}$ & & $2(1 \%)$ & $7(4 \%)$ & $4(8.3 \%)$ & $\ddagger$ \\
\hline Reoperation and $\mathrm{MI}>\mathrm{II}^{\circ}$ & & - & $2(1.2 \%)$ & $5(10.5 \%)$ & $\ddagger$ \\
\hline Mitral annulus diameter (mm) & $37.4 \pm 4$ & $31.2 \pm 3$ & $33.9 \pm 4$ & $35.7 \pm 4$ & $<.01^{*}$ \\
\hline Clinical status (NYHA functional class) & $3.0 \pm 0.4$ & & $0.6 \pm 0.8$ & $0.8 \pm 0.8$ & $<.01 \dagger$ \\
\hline
\end{tabular}

$\overline{L V E D D}$, Left ventricular end-diastolic diameter; $M I$, mitral insufficiency; $N S$, not significant. * $P$ : discharge versus 5 years postoperatively. $\dagger P$ : preoperative versus 5 years postoperatively. $\$$ Percentages calculated from the number of patients in follow-up.

death. Other causes of death were severe pneumonia and lung cancer, respectively. Actuarial survival at 77 months, including early mortality, was $87.2 \%$ (Figure 1 ).

Regarding clinical status, a significant symptomatic improvement in NYHA functional class was obvious, averaging from $3.0 \pm 0.4$ preoperatively to $0.6 \pm 0.8$ at 1 year postoperatively and $0.8 \pm 0.8$ at 5 years $(P<.01)$.

\section{Reoperation}

Five (2.3\%) patients required reoperation during follow-up. The causes were repair related in all cases, including annulus redilatation in all patients, additional prolapse of the posterior leaflet in 2 patients, and restriction of the posterior leaflet in 1 patient. All patients had initially minimally invasive mitral valve repair or primary imperfect results. At reoperation, all valves were repaired again except one. Overall freedom from reoperation was $95.1 \%$ at 77 months (Figure 2). The PTFE sutures remained in situ and within a thick strip of scar, and no detachment at the trigones could be observed. Ring dilatation occurred by straightening of the continuous suture.

\section{Echocardiographic Results}

Echocardiographic examinations were performed in all surviving patients with mitral repair before discharge $(100 \%$ completeness) and at 1 year $(\mathrm{n}=164,93.7 \%$ completeness $)$ and 5 years $(\mathrm{n}=48,82.7 \%$ completeness) postoperatively. During this period, the mean mitral transvalvular gradients

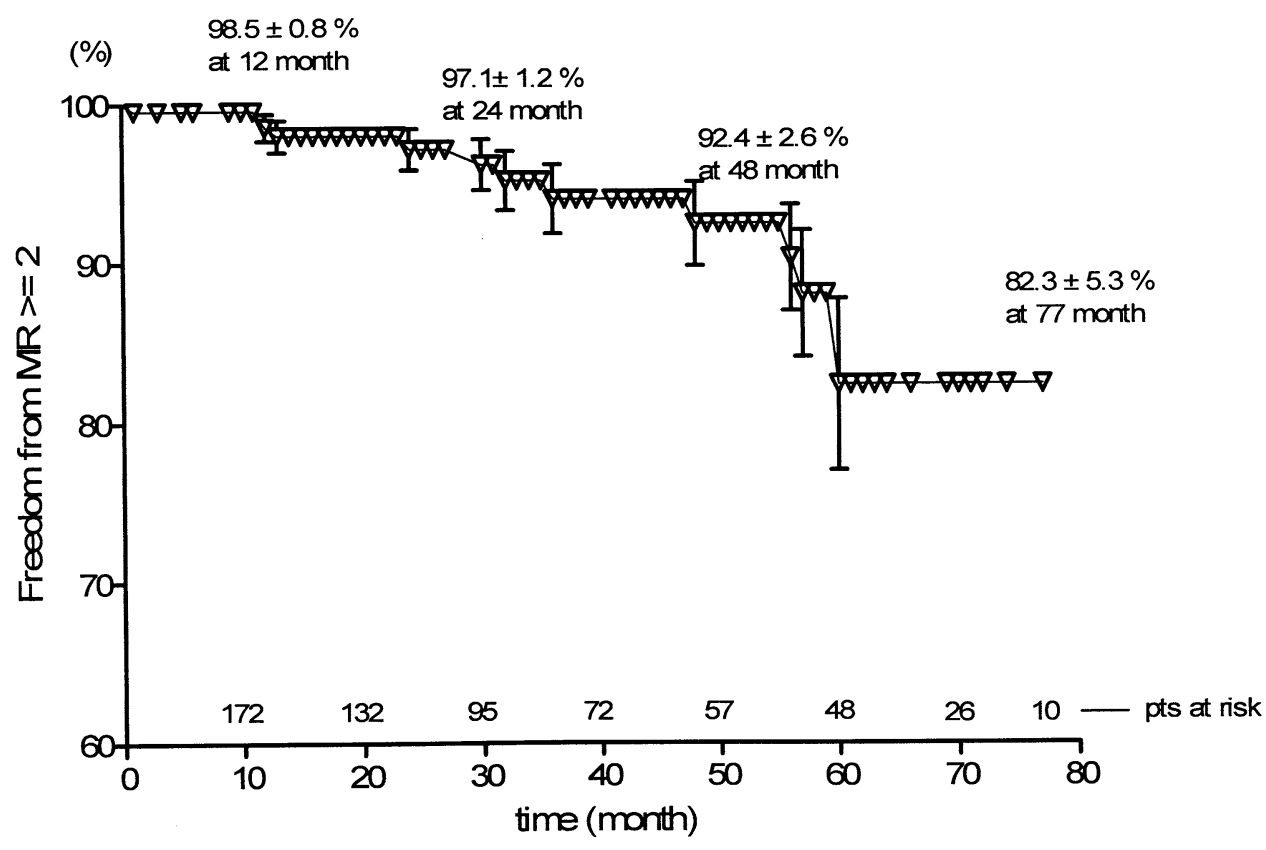

Figure 3. Freedom from nontrivial residual mitral regurgitation (grade 2 or greater). 


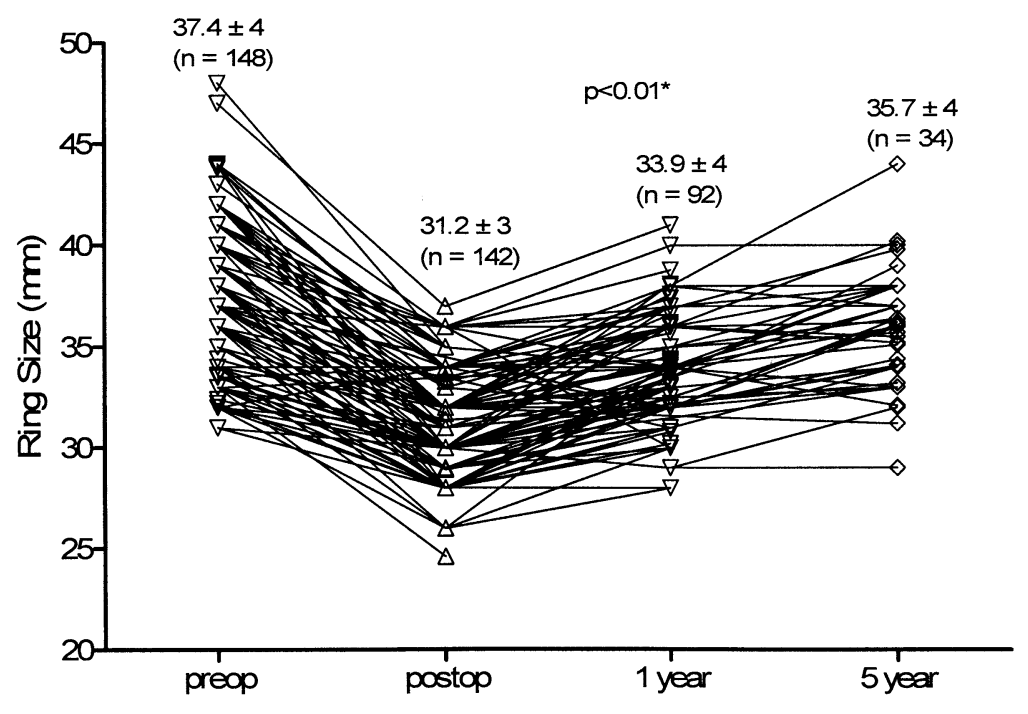

Figure 4. Echocardiographic measurement of mitral annulus shown as difference between preoperative and discharge values, values at discharge and 1 year postoperatively, and values at 1 and 5 years postoperatively. ${ }^{*} \boldsymbol{P}<.01$, discharge versus 5 years postoperatively.

were always low and did not significantly increase, measuring $2.1 \pm 0.9 \mathrm{~mm} \mathrm{Hg}$ at 1 year and $2.0 \pm 0.8 \mathrm{~mm} \mathrm{Hg}$ at 5 years. Accordingly, the calculated mitral valve opening area did not significantly change during the years of follow-up and averaged $3.2 \pm 1.0 \mathrm{~cm}^{2}$ at discharge, $3.3 \pm 0.9 \mathrm{~cm}^{2}$ at 1 year, and $3.1 \pm 0.6 \mathrm{~cm}^{2}$ at 5 years (Table 3 ).

Mitral valve insufficiency was significantly reduced early postoperatively. The mean postoperative grade averaged 0.25 \pm 0.5 in contrast to the preoperative grade of $3.1 \pm 1.1$. At the 1- and 5-year follow-up, we have not observed increase of the mean regurgitation grade in our patients (Table 3). Freedom from nontrivial residual mitral regurgitation was $82.3 \%$ at 77 months after the operation (Figure 3).

However, a progressive mitral annular dilatation was observed in the follow-up. At discharge, the mean mitral annular diameter was measured by means of echocardiography to be $31.2 \pm 3 \mathrm{~mm}(\mathrm{n}=142)$, a value that increased to $33.9 \pm 4 \mathrm{~mm}$ at 1 year $(\mathrm{n}=92)$ and even further progressed to $35.7 \pm 4 \mathrm{~mm}$ at 5 years $(P<.01, \mathrm{n}=34)$. The mitral annulus diameter was statistically analyzed by determining individual annulus dilation over the years. Taking the discharge values as baselines, the intraindividual differences at the 1- and 5-year follow-up points were significant (Figure 4). Left ventricular end-diastolic diameter significantly decreased after the operation over the years (Table 3).

\section{Discussion}

The technique of mitral valve reconstruction described by Carpentier and colleagues is completed by implanting a prosthetic ring to reinforce and shape the mitral valve annulus. This technique is widely used, with good long-term results. ${ }^{2,20}$ Disadvantages seen with ring annuloplasty include impairment of overall annular contraction during sys- tole and therefore left ventricular systolic function. ${ }^{5,6}$ As reported by Van Rijk-Zwikker and coworkers, ${ }^{24}$ a rigid ring significantly restricts the motion of the basal left ventricular wall as well. This finding has been confirmed in experimental settings by the Stanford group. ${ }^{11}$ In contrast, the potential advantages of suture annuloplasty over ring annuloplasty are believed to include better preservation of overall annular motion, as well as a lack of effect on posterior leaflet mobility. ${ }^{25}$ It avoids the possibility of distortion of the anterior leaflet, as well as pushing up a commissure. The costs of the procedure are reduced by avoiding an implant, and the risk of infection or hemolysis might be decreased.

In March 1996, semicircular suture annuloplasty was introduced in our institution as an alternative to prosthetic ring annuloplasty. This technique, known as the MASS procedure, was first reported in 1990 by Frater and Sisto. ${ }^{15}$ It should offer flexibility to the mitral annulus and preserve the physiologic function and geometry of the mitral valve while stabilizing the annulus, as well as reducing the mitral orifice to the same size as the anterior leaflet. We have modified this technique by using ePTFE (Gore-Tex) sutures instead of polypropylene sutures. In contrast to polypropylene sutures, the ePTFE suture allows tissue ingrowth, potentially ensuring long-term durability. Others have come to the same finding. ${ }^{26,27}$ The correct size of the mitral annulus was determined by varying the distance between the stitches and varying the tension, although in general the running suture, limited by tissue compressibility, matched the ring size to the size of the anterior leaflet. Mostly, diameter reduction appeared sufficient after completing one circumference of the suture line. When necessary, the second line could further tighten the ring. In fact, secondary readjustment of the suture after testing with intraventricular injection of saline solution was only exceptionally neces- 
sary in our hands. In contrast to our first impression, this technique is not a means to completely avoid SAM situations.

Our early results ${ }^{17}$ showed superior hemodynamic performance after the MASS procedure over ring annuloplasty in terms of mean valve gradients and mitral valve opening areas. As the etiology of the groups operated on either by using sutures or ring annuloplasty was different, we preferentially implanted prosthetic rings in ischemic or secondary mitral incompetence due to ventricular dilatation. Thus, the homogeneity of the groups was lost. Therefore we could not include comparative follow-up data in this report. However, the persistence of satisfactory hemodynamic performance was confirmed by the 1- and 5-year follow-up echocardiographic examinations and might be due to preservation of the flexibility and physiologic function of the mitral valve.

The operative mortality rate of $3.1 \%$ is well comparable with rates cited in the literature. ${ }^{19,20}$ In 3 patients functional occlusion of the circumflex artery was proved by means of postoperative angiography. Two of them had an anomalous course of the circumflex artery and extensive anterior commissure resection, respectively. Bulking of the tissue between the mitral annulus at the P1 segment and the base of the left atrial appendage might well be associated with a higher incidence of left circumflex artery injury. Concomitant exclusion of the left atrial appendage also bears this risk. However, we have observed circumflex occlusion in a pediatric patient with partial suture annuloplasty. By this, we attribute this complication to suture annuloplasty. To our knowledge, this complication with the MASS procedure has not been reported elsewhere yet. However, there are reports of a significantly higher incidence of myocardial ischemia after mitral repair $(5.4 \%)$ in comparison with replacements $(0 \%)$ in a series on 335 patients. ${ }^{28}$ All of the ischemic events involved the inferior wall. The authors attributed this complication to air embolism at the time of testing valve competence with saline injection into the left ventricle.

We used a minimally invasive approach in 150 patients through a right-sided minithoracotomy. Although being technically more demanding, operative times were not prolonged. Suture annuloplasty might be a technique that is simpler to perform in minimally invasive mitral valve surgery. Annulus stabilization is performed by using a single running suture with less need for knot tying as required for prosthetic ring implantation. In 8 patients we detected unacceptable residual mitral regurgitation intraoperatively. All underwent complex mitral valve repair, and 6 of them had a minimally invasive approach. Intraoperative secondary valve replacement might be as well attributable to the learning curve for the limited approach.

In our study the patients had predominantly a degenerative cause of mitral regurgitation. Degenerative valves have been shown to have the best perioperative outcomes and superior midterm and long-term repair prognoses in com- parison with valves with other causes of mitral regurgitation. To date, 5 (2.3\%) patients have returned for reoperation because of progressive valve regurgitation. They all had primarily nontrivial regurgitation.

Overall, freedom from nontrivial mitral regurgitation was $83.2 \%$ at 77 months after the operation, a score not comparable with best results from ring annuloplasty. ${ }^{19,20}$

In addition, we found significant and progressive postoperative mitral annulus dilatation in the years of follow-up. These facts have raised some doubts about the durability of the procedure. There are insufficient data to make a definite statement regarding the durability of this procedure, and a longer follow-up is warranted. Deloche and associates ${ }^{20}$ reported an early reoperation rate of $4.3 \%$, whereas Galloway and coworkers ${ }^{29}$ noted a rate of reoperation of $2.9 \%$ with the Carpentier-Edwards annuloplasty ring, which is comparable with our results. The lack of ring annuloplasty was found by Cohn and colleagues ${ }^{30}$ to be a risk factor for reoperation. Overall freedom from reoperation was $95.1 \%$ at 77 months.

Most of our patients undergoing reoperation had annular dilatation and recurrent changes of the leaflets. Stable annuloplasty reduces mitral valve area to less than natural size. As load calculates from pressure by area, stable annuloplasty should constantly reduce leaflet stress. Therefore in the meantime we changed our technique and use a partial flexible prosthetic band.

In conclusion, the present study demonstrates that by reinforcing the mitral ring with a suture annuloplasty, similar perioperative results as with prosthetic ring implantation can be achieved. Transvalvular gradients are consistently low, and midterm stability of repair and reoperation rates are comparable with those seen in other series. Continuous redilatation of the annulus raises concerns about further long-term stability. Additionally, there is an increased risk of circumflex artery injury. The present study suggests that the MASS procedure might not be a durable annular remodeling technique. At midterm, the majority of repairs do not depend on a stable ring size reduction.

\section{References}

1. Gillinov AM, Faber C, Houghtaling PL, et al. Repair versus replacement for degenerative mitral valve disease with coexisting ischemic heart disease. J Thorac Cardiovasc Surg. 2003;125:1350-62.

2. Braunberger E, Deloche A, Berrebi A, et al. Very long-term results (more than 20 years) of valve repair with Carpentier's techniques in nonrheumatic mitral valve insufficiency. Circulation. 2001;104 (suppl I):I8-11.

3. Enriquez-Sarano M, Schaff HV, Orszulak TA, Tajik AJ, Bailey KR, Frye RL. Valve repair improves the outcome of surgery for mitral regurgitation: a multivariate analysis. Circulation. 1995;91:1022-8.

4. Ren JF, Aksut S, Lighty GW Jr, et al. Mitral valve repair is superior to valve replacement for the early preservation of the cardiac function: relation of the ventricular geometry to function. Am Heart J. 1996; 133:974-81. 
5. David TE, Komeda M, Pollick C, Burns RJ. Mitral valve annuloplasty: the effect of the type on left ventricular function. Ann Thorac Surg. 1989;47:524-8.

6. Ormiston JA, Shah PM, Tei C, Wong M. Size and motion of the mitral valve annulus in man. A two-dimensional echocardiographic method and findings in normal subjects. Circulation. 1981;64:113-20.

7. Gillinov AM, Cosgrove DM 3rd, Shiota T, et al. Cosgrove-Edwards Annuloplasty System: midterm results. Ann Thorac Surg. 2000;69: 717-21.

8. Fasol R, Meinhart J, Deutsch M, Binder T. Mitral valve repair with the Colvin-Galloway Future Band. Ann Thorac Surg. 2004;77:1985-8.

9. Jebara VA, Mihaileanu S, Acar C, et al. Left ventricular outflow obstruction after mitral valve repair: results of sliding leaflet technique. Circulation. 1993;88(part 2):30-4.

10. Dagum P, Green GR, Glasson JR, et al. Potential mechanism of left ventricular outflow tract obstruction after mitral ring annuloplasty. J Thorac Cardiovasc Surg. 1999;117:472-80.

11. Green GR, Dagum P, Glasson JR, et al. Restricted posterior leaflet motion after mitral ring annuloplasty. Ann Thorac Surg. 1999;68: 2100-6.

12. Matsuda H, Shintani H, Taniguchi K, et al. Semicircular suture annuloplasty for mitral regurgitation: appraisal of the Paneth-Burr method. J Heart Valve Dis. 1997;6:48-53.

13. Duebener LF, Wendler O, Nikoloudakis N, Georg T, Fries R, Schäfers HJ. Mitral-valve repair without annuloplasty rings: results after repair of anterior leaflet versus posterior-leaflet defects using polytetrafluoroethylene sutures for chordal replacement. Eur J Cardiothorac Surg. 2000;17:206-12.

14. Barlow CW, Ali ZA, Lim E, Barlow JW, Wells FC. Modified technique for mitral repair without ring annuloplasty. Ann Thorac Surg. 2003;75:298-300.

15. Frater RWM, Sisto D. Mural annulus shortening suture (MASS) for annuloplasty. J Cardiovasc Surg. 1990;31:10.

16. Burr LH, Krayenbuhl C, Sutton MS, Paneth M. The mitral plication suture: a new technique of mitral valve repair. $J$ Thorac Cardiovasc Surg. 1977;73:589-95

17. Detter C, Aybek T, Kupilik N, Fischlein T, Moritz A. Mitral valve annuloplasty: comparison of the mural annulus shortening suture (MASS) with the Carpentier-Edwards ring prosthetic ring. J Heart Valve Dis. 2000;9:478-86.
18. Chitwood WR Jr, Elbeery JR, Moran JF. Minimally invasive mitral valve repair using transthoracic aortic occlusion. Ann Thorac Surg. 1997;63:1477-9.

19. Carpentier A, Chauvaud S, Fabiani JN, et al. Reconstructive surgery of the mitral valve incompetence. Ten-year appraisal. J Thorac Cardiovasc Surg. 1980;79:338-48.

20. Deloche A, Jebara VA, Relland JYM, et al. Valve repair with Carpentier techniques. The second decade. J Thorac Cardiovasc Surg. 1990;99:990-1002.

21. Henry WL, DeMaria A, Gramiak R, et al. Committee on nomenclature and standards in two-dimensional echocardiography. Circulation. 1980;62:212-25

22. Edmunds LH, Clark RE, Cohn LH, et al. Guidelines for reporting morbidity and mortality after cardiac valvular operations. J Thorac Cardiovasc Surg. 1996;112:708-11.

23. Kaplan EL, Meier P. Nonparametric estimation from incomplete observations. J Am Stat Assoc. 1958;53:457-81.

24. Van Rijk-Zwikker GL, Mast F, Schipperheyn JJ, Huysmans HA, Bruschke AV. Comparison of rigid and flexible rings for annuloplasty of the porcine mitral valve. Circulation. 1990;82(suppl IV):IV58-64.

25. Tibayan FA, Rodriguez F, Liang D, Daughters GT, Ingels NB Jr, Miller DC. Paneth suture annuloplasty abolishes acute ischemic mitral regurgitation but preserves annular and leaflet dynamics. Circulation. 2003;108(suppl II):II128-33.

26. Nagy ZL, Bodi A, Vaszily M, Szerafin T, Horvath A, Peterffy A. Five-year experience with a suture annuloplasty for mitral valve repair. Scand Cardiovasc J. 2000;34:528-32.

27. Minatoya K, Okabayashi H, Shimada I, et al. Pathologic aspects of polytetrafluoroethylene sutures in human heart. Ann Thorac Surg. 1996;61:883-7.

28. Obarski TP, Loop FD, Cosgrove DM, Lytle BW, Stewart WJ. Frequency of acute myocardial infarction in valve repairs versus valve replacement for pure mitral regurgitation. Am J Cardiol. 1990;65:887-90.

29. Galloway AC, Grossi EA, Bizekis CS, et al. Evolving techniques for mitral valve reconstruction. Ann Surg. 2002;236:288-93.

30. Cohn L, Couper G, Aranki S, et al. Long-term results of mitral valve reconstruction for regurgitation of the myxomatous mitral valve. J Thorac Cardiovasc Surg. 1994;107:142-51. 